\title{
La fi d'una llegenda: Arnau de Vilanova davant la màgia i l'astrologia" Sebastià Giralt
}

Durant segles el metge i reformador espiritual Arnau de Vilanova (c. 1240-1311) va ser vinculat a les més variades branques de l'ocultisme -la màgia, la nigromància, l'astrologia, l'alquímia, l'oniromància - fins a esdevenir un mestre llegendari de les arts ocultes. Alhora, en consonància amb aquesta fama, li van ser atribuïdes apòcrifament obres sobre aquestes disciplines, que al seu torn contribuien a fomentar la seva llegenda. La recerca desenvolupada al llarg dels segles $X X$ $i$ XXI ha permès recuperar la figura històrica $i$ l'obra autèntica d'Arnau: n'ha sorgit una visió de la seva actitud davant la màgia i l'astrologia molt menys heterodoxa, que no traspassa els límits oscillants establerts per les elits intel-lectuals del seu temps. Aquest article se centrarà a presentar el pensament i la pràctica del veritable Arnau entorn dels dos vessants principals de la màgia medieval —la nigromància i la màgia natural-, així com de l'astrologia, àmbit en què caldrà discriminar la seva obra autèntica de l'espúria. En canvi, es deixaran de banda altres arts ocultes que els estudiosos d'avui ja desvinculen totalment d'Arnau de Vilanova, inclosa l'alquímia, que li va donar una gran reputació durant l'edat mitja-

\footnotetext{
* Aquest treball s'inscriu en el projecte Corpus digital de Arnau de Vilanova: filosofia y ciencia en la corona de Aragón (siglos XIII-

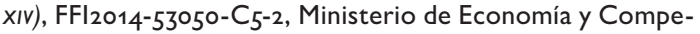
titividad.
}

na i l'època moderna gràcies a un extens corpus d'obres que van circular sota el seu nom però que en l'actualitat es consideren totes apòcrifes (Calvet 2011).

\section{La reprovació de la nigromància}

La primera obra d'Arnau que tracta un aspecte relatiu a les arts ocultes i l'única que aborda de manera monogràfica la màgia és la breu Epistola de reprobacione nigromantice ficcionis, dedicada al bisbe de València Jaspert de Botonac (Giralt 2005). S'ha de datar entre el 1276 i el 1288, atès que Jaspert va ser al capdavant de la diòcesi valentina durant aquest període $\mathrm{i}$ es desprèn del text que l'havia escrit recentment a demanda dels membres d'una comunitat de religiosos on s'hostatjava mentre esperava que el mar li permetés emprendre la navegació.

L'epístola és un atac a la creença en la nigromància, tal com s'anomenava la màgia basada en la invocació dels esperits, identificats amb els dimonis i, per tant, rebutjada per l'ortodòxia cristiana. El nucli del text és una argumentació escolàstica (questio) contra el principi fonamental d'aquesta pràctica: la possibilitat de forçar un esperit o dimoni a complir les ordres de qui l'invoca. L'argumentació pretén demostrar que no existeixen forces naturals o sobrenaturals 


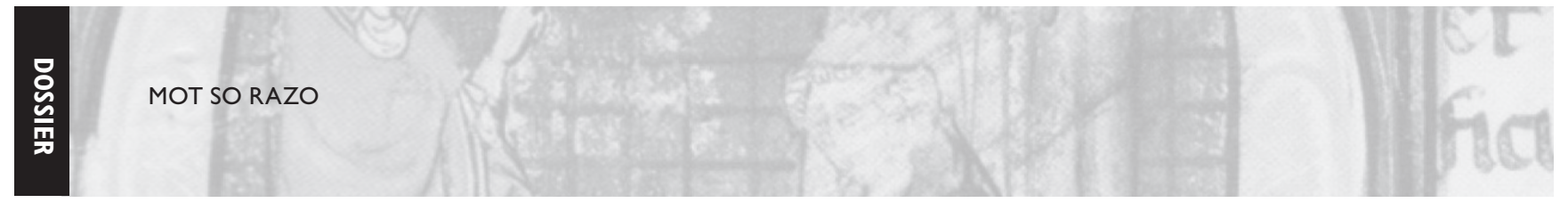

a l'abast dels éssers humans que els permetin sotmetre els dimonis, llevat de la gràcia de Déu concedida als homes sants, i amb la finalitat de demostrar-ho descarta un a un tots els recursos amb què una persona creu dominar-los, començant pels naturals i acabant pels sobrenaturals. Tots aquests mitjans, segons Arnau, no són més que invencions dels mateixos diables per enganyar els homes amb la intenció de perdre'ls. En això consisteix l'engany nigromàntic (nigromantica ficcio) que dóna nom a la carta. Des del perfecte coneixement del món natural i de la psicologia humana els dimonis han creat amb astúcia un extens ventall de mitjans diversos per invocar-los, en els quals fingeixen ser obligats pels nigromants a complir els seus desitjos.

El De reprobacione és un exemple perfecte de la concepció de la màgia diabòlica com un engany, que va ser la posició predominant fins a les primeres dècades del segle XIV. Després s'imposarà la creença en l'existència real del pacte amb el diable, que duria a la condemna de nigromants $\mathrm{i}$ bruixes per heretgia (Martí 2009). Tot i l'absència total de citacions a les autoritats escolàstiques, la metodologia escolàstica i alguns dels continguts poden reflectir la influència d'autors com Guillem d'Alvèrnia, Albert Magne i Roger Bacon, encara que el text més proper, i potser l'inspirador, sembla ser l'article $\mathrm{VI}, 10$ de les Questiones de potentia de Tomàs d'Aquino. De tota manera, Arnau hi presenta un contingut tan original com el dels intellectuals més destacats de la seva època. Malgrat tot, el que dóna un caràcter únic a l'epístola arnaldiana és el fet que poa de tres tradicions diferents: no tan sols del pensament escolàstic tant teològic com filosoficonatural— sinó també de la mateixa tradició màgica àrab i de la medicina arabollatina.

En efecte, a diferència d'altres autors contemporanis, la reprovació arnaldiana es basa en un coneixement directe de la màgia adreçada als esperits del món islàmic, ja que, segons les seves pròpies paraules, l'autor ha llegit tota la doctrina sobre la invocació dels esperits en les fonts àrabs i no cristianes, fins i tot en la llengua original. Concretament Arnau cita dos títols poc o gens coneguts a través d'altres fonts: el Liber de fantasmatibus i els Libri centri et circumferencie.
Finalment, cal destacar l'originalitat del recurs a la medicina per atacar la nigromància (Giralt 2005: 37-52; 2017). En efecte, en l'última part de l'epístola apareix l'Arnau metge, quan, com a única excusa possible per a aquells que defensen la nigromància en tant que un coneixement tècnic i racional, es fa constar que una creença tan errada i contrària a la veritat i la intel-ligència s'ha d'atribuir a una lesió de la raó causada per una malenconia innata o sobrevinguda. Tanmateix, segons l'autor, es tractaria d'una malenconia oculta. Aquesta diagnosi té un fonament pr oblemàtic: Arnau justifica la malaltia dels nigromants sobre la base de la «doctrina de Galè sobre els gèneres ocults de la malenconia», però, segons tots els indicis, la citació no respon directament a cap passatge de Galè, sinó a la tradició que deriva d'aquest metge grec, en concret a una formulació propera al De melancholia de Constantí l'Africà, versió llatina d'un tractat àrab d'Ibn Ishaq Imran (segles IX-X). Constantí esmenta dos gèneres de malenconia «molt ocults i obscurs», probablement en una interpretació distorsionada de l'original àrab. Llavors, per què Arnau atribueix la citació a Galè? Podem pensar en diverses raons: un simple error, la falsa atribució del De melancholia a Galè o una mala disposició per citar un Constantí desacreditat com a traductor o, més generalment, els autors contemporanis, evitats per Arnau.

Arnau no és el primer ni serà l'últim que relacioni la màgia diabòlica o la bruixeria amb la malenconia. Tanmateix, la seva formulació i la seva motivació són originals. Mentre que tradicionalment es creia que la malenconia podia convertir-se en una porta a la possessió demoníaca, la posició d'Arnau respon més aviat a les idees heretades de les tradicions mèdiques de l'antiguitat sobre els danys causats per les facultats cognitives dels melancòlics. El De reprobacione és el primer escrit d'Arnau on atribueix trastorns mentals a qui defensa idees considerades per ell com a errònies. Però també trobarem el mateix procediment en algunes de les seves controvèrsies espirituals posteriors amb teòlegs escolàstics. Així doncs, podem deduir que Arnau tergiversa la seva font mèdica amb la finalitat de desacreditar les idees dels seus adversaris dialèctics, tant 


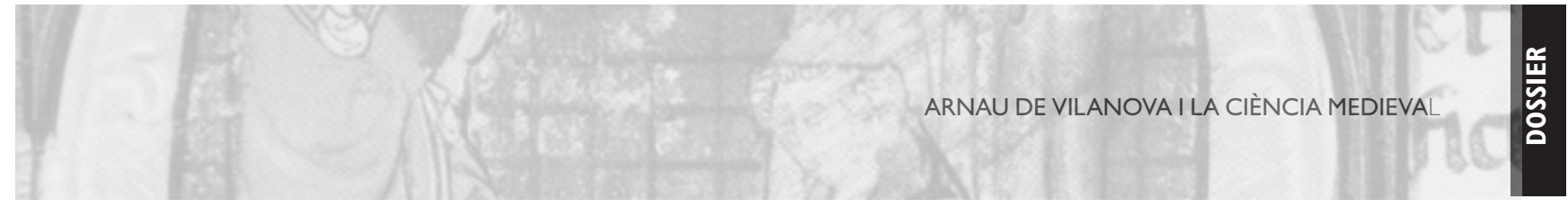

LA LLEGENDA D’ARNAU DE VILANOVA

La figura d'Arnau de Vilanova, igual que la d'altres savis medievals prominents, va ser des de ben aviat envoltada d'una aurèola de misteri i llegenda. Els orígens del mite d'un Arnau expert en arts ocultes es poden rastrejar fins i tot en els seus textos: en el Raonament d'Avinyó (1310) es queixa de les acusacions de nigromant i fetiller que rebia dels seus perseguidors, a causa de les seves idees espirituals (Batllori 1947: 215). En realitat va ser tot un conjunt de factors diversos el que va contribuir a crear el mite de l'Arnau ocultista i a enriquir-lo amb nous aspectes en el decurs dels segles. Sens dubte hi van tenir un paper important el profetisme apocalíptic d'alguns dels seus escrits espirituals, els seus conflictes amb l'establishment eclesiàstic i la condemna pòstuma de la seva obra espiritual. Altres causes podrien haver estat l'interès mostrat per la càbala en alguns dels seus escrits teològics i per l'astrologia i la màgia natural en els mèdics, així com alguns episodis de la seva vida susceptibles d'una lectura en clau esotèrica, com la interpretació dels somnis dels reis Jaume II i Frederic III. També hi degueren influir les sospites que van planar sobre ell d'haver estat còmplice, per mitjà de màgia negra, en el presumpte assassinat del papa Benet XI (1304) — pel qual va ser acusat Bernat Deliciós-, segons van declarar uns testimonis en el procés celebrat el 1319 contra aquest líder dels franciscans espirituals.
A mitjan segle XIV, una volta ja se li havien començat a atribuir espúriament tractats alquímics, trobem el primer esment de la llegenda d'un Arnau alquimista quan Giovanni d'Andrea li atribueix la fabricació de varetes d'or en la cort pontifícia. Aquesta tradició s'enriquirà al segle Xv i en reportaran noves gestes fabuloses, com ara la introducció de Ramon Llull en l'art alquímica gràcies al seu magisteri o la creació alquímica d'un homuncle o petit ésser humà, que el mestre va interrompre quan el cos ja s'estava desenvolupant per por de desafiar Déu.

A la fi del mateix segle apareix l'Arnau profeta-astròleg, quan autors com Hartmann Schedel o Giovanni Pico della Mirandola atribueixen a l'anunci de la fi del món d'Arnau un fonament astrològic que ell havia negat. Al segle XVI la divulgació a través de la impremta acabarà de fixar el mite arnaldià, tot fusionant les tres llegendes sorgides independentment durant els dos segles precedents -l'Arnau nigromant, l'alquimista i el profeta-astròleg - en una imatge arquetípica del metge-mag que, gràcies al mestratge en una extensa diversitat de sabers, podia curar i dominar les forces del cel i de la natura. Si bé aquest ideal encaixava amb l'hermetisme renaixentista, d'arrel neoplatònica, i més tard amb el paracelsisme, també va provocar el rebuig dels detractors de les arts ocultes (Giralt 2013a). si són els temptats per la nigromància com els detractors de les seves obres religioses: no els pot diagnosticar un dany a la facultat racional sense especificar que és l'únic símptoma visible del seu desordre, atès que lògicament ells semblen sans en tots els altres aspectes, i en aquest punt s'allunya de la seva font constantiniana, que descriu, a més, altres signes de la malenconia oculta comuns a la resta d'espècies de la malenconia.

\section{Les propietats ocultes en la medicina d'Arnau}

Com Arnau, el conjunt dels intel-lectuals medievals condemnava la nigromància, però això no vol pas dir que rebutgessin totes les pràctiques que podem qualificar de màgiques. En efecte, l'anomenada per Guillem d'Alvèrnia «màgia natural» tenia un espai dins la filosofia natural escolàstica, ja que la seva finalitat era conèixer i explotar els mecanismes de la natura. Tot i aquesta relació, els escolàstics medievals distingien entre un coneixement racional ben explicat en el marc de la seva concepció física de l'univers i un coneixement, sovint també molt útil, que només es podia adquirir per experiència perquè escapava a la raó. D'aquest darrer s'ocupava la màgia natural, fonamentada en les propietats ocultes existents en la natura i, com que aquestes propietats provenien dels astres, estava estretament vinculada a l'astrologia no espiritualista. A la baixa Edat Mit- 


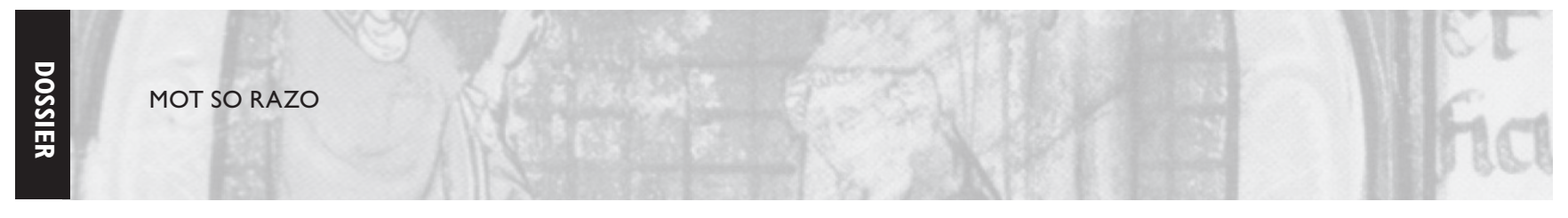

jana l'existència d'aquestes propietats era opinió comuna tant en la filosofia natural com en el galenisme, la doctrina mèdica que es difonia des de les universitats derivada de Galè i enriquida pels àrabs. El seu aprofitament era generalment considerat lícit. Tot i així, les fronteres entre els efectes atribuiits a les propietats ocultes, d'origen natural, i els causats per éssers sobrenaturals invocats pels nigromants —els dimonis - eren objecte de discussió i posaven en evidència diverses actituds dels pensadors de l'època davant els límits de la natura i de la intervenció diabòlica. Així mateix, cal advertir que la

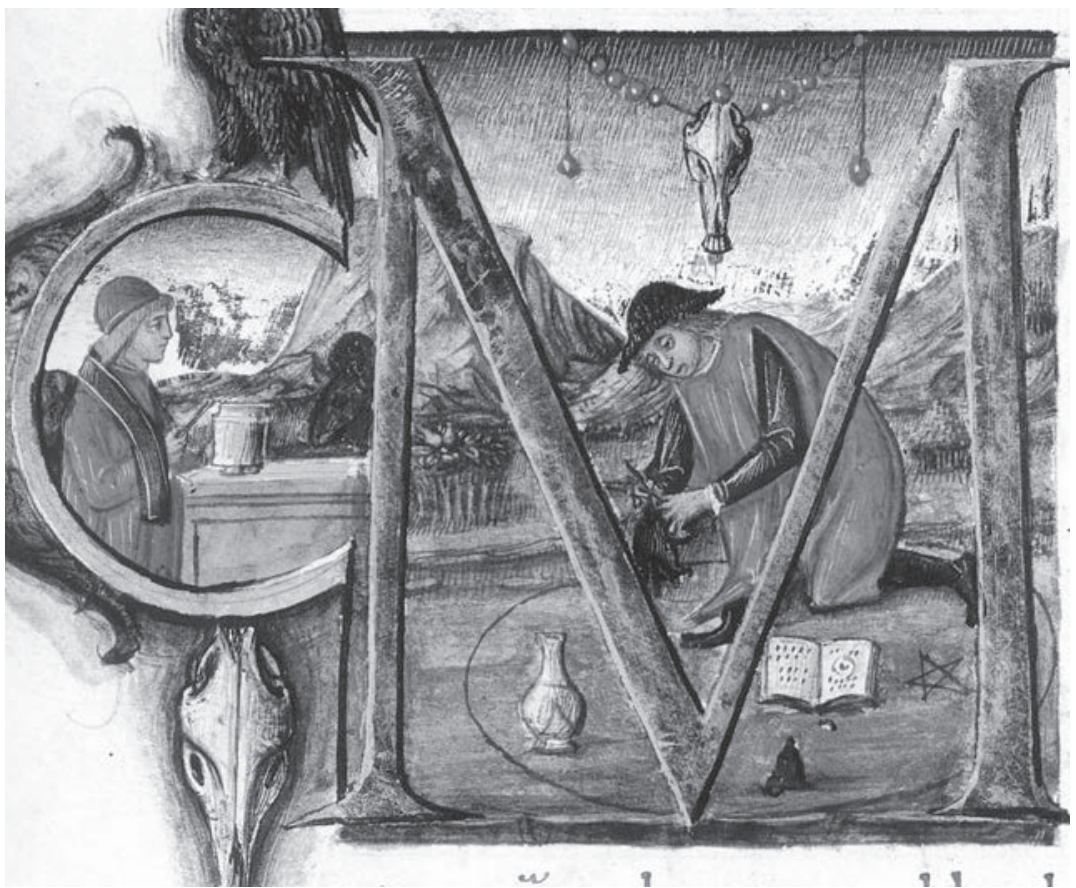

Un nigromant dibuixa un cercle (Història natural de Plini el Vell, 1481, Venècia, Biblioteca Marciana) terminologia referent a les arts ocultes varia d'un autor a un altre: en realitat, la denominació màgia natural no es va estendre fins al Renaixement i la majoria d'autors medievals, com el mateix Arnau, no qualificaven l'ús d'aquestes propietats de màgia, un terme que solia tenir connotacions negatives (Giralt 2011).

Alguns dels textos més clarificadors per definir les propietats ocultes són d'Arnau de Vilanova (Weill-Parot 2002: 459-470; Giralt 2008), especialment en la Pars operativa (Arnau 1520: 126V-127r) i I'Speculum medicine (McVaugh, en premsa, cap. 78). S'hi exposa que tot el que és creat sota el cel, sigui mineral, vegetal, animal o artificial, rep unes propietats ocultes procedents de la influència dels astres, unes vegades conegudes i d'altres no. El seu coneixement i la seva utilització presenten una extrema dificultat perquè no són accessibles a la raó com les qualitats comunes, sinó tan sols per l'experiència. Per això Arnau de vegades les anomena virtus occulta, però amb més freqüència només proprietates. La designació que s'acabarà imposant serà la de propietats ocultes.

És fonamental la distinció que estableixen Arnau i altres autors entre les facultats específiques i les individuals, ja que les segones poden ser ve- hiculades per la tècnica. En efecte, la proprietas rep el nom de forma specifica quan es dóna en tots i cadascun dels individus de l'espècie, encara que s'hi produeixin variacions de grau. Però en altres ocasions és exclusivament individual, provocada de manera accidental per una concurrència de factors, per exemple una poderosa posició dels astres en el moment en què l'individu és engendrat o neix, o bé, si es tracta d'un objecte de creació humana com les imatges astrològiques, quan se'n culmina la fabricació. Fins i tot les persones poden posseir aquestes propietats, cosa que explica que alguns mags aconsegueixin efectes extraordinaris i que certs malalts empitjorin a causa de la proximitat d'una certa persona. Tals efectes es deuen als vapors que desprenen, d'acord amb la teoria medieval de la fascinatio, la transmissió del poder de l'ànima a través del propi cos i l'aire fins a afectar altres cossos. Així mateix, les propietats ocultes poden alterar els elements que influeixen en l'ambient de manera que il.luminen el cervell fins a entendre el que està ocult o albirar el futur, segons la idea de l'endevinació natural (Giralt 2013b), o bé n'obstaculitzen o n'impedeixen el funcionament. En aquest darrer cas ens trobem amb la ligatio, 
un tipus específic de propietats ocultes que perjudiquen les operacions fisiològiques o mentals. La seva acció es descriu amb el verb ligare, és a dir impedir la realització d'una operació pròpia d'un òrgan o d'un element. Entre els exemples que cita hi ha el segell astrològic de Leo, que impedeix als sentits percebre el dolor del càlcul, i certes plantes, pedres o animals que priven de les funcions sexuals. Atès que la ligatio provoca disfuncions físiques o mentals, Arnau mostra un interès especial a tractar-la a causa de les seves importants repercussions mèdiques.

En efecte, en els escrits mèdics d'Arnau trobem al/lusions a les propietats ocultes no solament com a origen de disfuncions patològiques sinó sobretot com a fonament de remeis que ens poden resultar més o menys sorprenents pel seu caire màgic, com per exemple suspensions aplicades sobre els peus d'un imant o de les potes d'una granota, d'una àguila o d'una tortuga, amb l'objectiu de calmar el dolor de la gota. Ara bé, no és únicament l'acció de les suspensions la que s'explica per les propietats ocultes sinó també la de certs compostos farmacològics com la triaga o determinats simples que poden entrar en la composició d'alguns fàrmacs.

A partir d'aquests exemples i d'altres referits per Arnau, és possible observar que determinats tipus de trastorns o drogues són especialment afectats per l'acció de les propietats ocultes. Hem vist que un d'ells és l'apaivagament del dolor d'un membre. Un altre àmbit són les malalties mentals, ja que Arnau considera la proprietas una de les causes de trastorns com l'alienació, la manca de memòria i la demència, que poden ser fins i tot provocades per un malefici. Per tant, per curar aquests desordres o alleujar-los cal desfer els maleficis, allunyar de l'habitació la persona o objecte que posseeix la proprietas nociva o bé aprofitar igualment les propietats ocultes presents en minerals, plantes, membres d'animals i segells zodiacals que puguin contrarestar-les. El tercer àmbit d'especial incidència de les propietats ocultes és l'acció dels verins i antídots, com veurem en el cas de la triaga. Per això trobem nombroses notícies que hi estan relacionades en la seva monografia sobre els verins (De venenis), provinents de textos i autors molt diversos - antics, àrabs, medievals llatins. Tanmateix són tres els autors que es revelen fonamentals en la formulació baixmedieval _ i arnaldiana en particular — del concepte de les propietats ocultes per a la seva aplicació terapèutica: Galè, Costa ben Luca i Avicenna.

Igual que Avicenna en el seu Cànon, Arnau desenvolupa una de les exposicions sobre les propietats ocultes en el marc de la teoria farmacològica general continguda en I'Speculum medicine (McVaugh 1975:115-122; McVaugh, en premsa). Parteix de la constatació que un compost farmacològic posseeix tres tipus de qualitats (virtutes complexionatorum). Les qualitats primàries són aportades per la complexió de cadascun dels seus constituents: calent, fred, sec i humit. Les qualitats dominants en un medicament corregeixen la discràsia del cos —el desequilibri en favor d'una de les qualitats que provoca la malaltia-, d'acord amb el principi expressat per l'axioma contraria contrariis, és a dir, es corregeix el desequilibri en un sentit per l'aplicació de remeis amb qualitats oposades. A més, un compost conté una forma mixtionis, la qual no només implica la suma de les qualitats primàries sinó que alhora en proporciona de secundàries al fàrmac. Tant les qualitats primàries d'un compost com les secundàries són previsibles per a la raó. Per contra, la qualitat terciària és la proprietas. Tot i que és possible esbrinar els seus efectes, la proprietas no és explicable a partir de les qualitats primàries ni es pot conèixer a través d'un experiment preparat racionalment, sinó, en tot cas, a través d'una experiència casual. A les Medicationis parabole Arnau arriba a afirmar que les propietats ocultes produeixen una acció medicinal molt més intensa que la derivada de la complexió (Paniagua, Ferre \& Feliu 1990: 42).

Entre els exemples de les propietats ocultes recollits en l'Speculum hi ha la triaga, el medicament més apreciat en la farmacopea galenista, compost d'un gran nombre d'ingredients, inclosa la carn d'escurçó. El primer autor de la facultat de Montpeller que en va tractar va ser probablement Arnau de Vilanova en la seva Epistola de dosi tyriacalium medicinarum. Hi explica que una de les aplicacions de la triaga és combatre els verins gràcies a la proprietas, però s'ha de donar la 


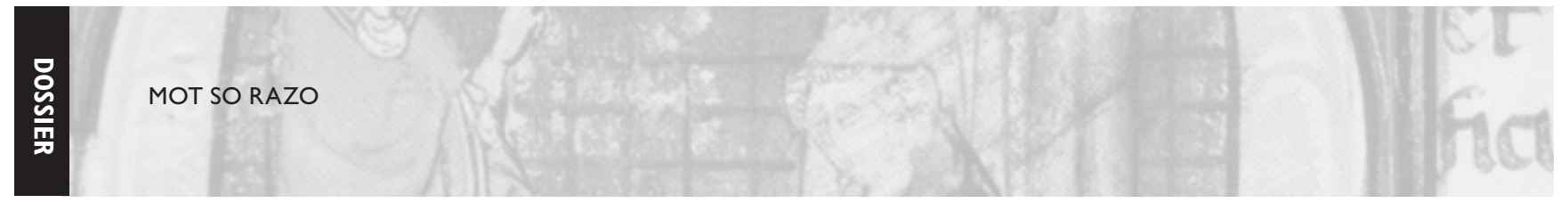

quantitat més petita que sigui efectiva i, per tant, abans de res cal esbrinar per mitjà de l'experiència quina n'és la dosi mínima que fa efecte i quina n'és la màxima. Així s'obté una guia segura per dosificar la seva aplicació segons exigeixin les circumstàncies particulars (McVaugh 1985: 86-90).

Per tant, la triaga exemplifica quan i com cal recórrer a l'experiència en el cas que la raó no arribi a explicar el funcionament de certs compostos o certs simples de gran utilitat gràcies a les seves propietats ocultes. Malgrat la preponderància donada per la medicina universitària als recursos que podia explicar racionalment, els remeis basats en la proprietas com la triaga suposaven un repte per al sistema escolàstic i deixaven un espai obert a l'experiència. Per això, no és sorprenent que algú pretengués elaborar una alternativa terapèutica al galenisme a partir de les propietats ocultes. Aquest va ser el cas de Nicolau de Polònia, dominic d'origen alemany que va estar a Montpeller entre 1250 i 1270. El seu poema Antipocras és una reacció mística contra la medicina racional i un cant a la medicina empírica fonamentada en les propietats ocultes. Per a Nicolau el més preuat dels medicaments és la triaga. Així s'entén que la seva col·lecció de receptes mostri predilecció per l'ús de serps, escorpins i gripaus (Sudoff 1916; Eamon \& Keil, 1987).

En el comentari del primer aforisme hipocràtic que Arnau adreça als seus estudiants, la Repetitio super aphorismo Hippocratis "Vita brevis», es pot observar aquesta tensió entre la ciència racional i l'experiència en relació a les propietats ocultes (McVaugh 2014: 210-213). D'una manera audaç dins el galenisme medieval, que tendeix a ser reticent davant les experiències noves, Arnau defensa que el metge pot recórrer a l'experimentació o l'experiència (experimentum) per comprovar els efectes nocius o beneficiosos d'un remei, d'acord amb el mètode que, segons hem vist, aconsella aplicar per esbrinar la dosi necessària de la triaga. S'hi refereix quan enumera les accions necessàries per treure profit de la recerca en medicina: en primer lloc estudiar escrupolosament l'herència dels antics, a continuació «experimentar amb cautela», després reflexionar-hi a fons i en últim lloc posar per escrit de manera sintètica el producte de l'experiència sobre el qual s'ha arribat a la certesa. Arnau, doncs, colloca l'experiència en un segon lloc prou destacat, al darrere del perfecte coneixement de la tradició mèdica. Però adverteix que ha de fer-se amb prudència, ja que, com diu el mateix aforisme hipocràtic, l'experimentum és falllaç o perillós. Per tant, exposa el mètode adequat per provar quins experimenta són acceptables i quins no ho són posant com a exemple l'assaig d'una terapèutica basada en les propietats ocultes. Si no es té cap notícia prèvia de l'experiència, no s'ha de procedir a l'aplicació directa interna o externa sinó que s'ha de recórrer a la suspensió, per poder apartar la substància del cos immediatament. En canvi, si la informació arriba a través d'algú altre, l'actitud del metge ha de ser més cautelosa si té un origen popular que no pas si prové d'una autoritat mèdica.

Com que l'experimentum que porta a descobrir una proprietas és sempre fortuit, i no pot ser un experimentum racional, que busca un objectiu prèviament determinat, Arnau arriba a reconèixer que els practicants d'una medicina no culta tenen la mateixa possibilitat que els savis de descobrir per atzar la proprietas d'una substància i, en conseqüència, aquests poden rebre certes informacions d'aquells. Tanmateix, adverteix que un metge, abans d'aplicar un recurs d'origen popular, ha de prendre dues precaucions. De primer ha de considerar si aquest recurs repugna a la raó i, si és el cas, rebutjar-lo. En segon lloc ha de confirmar si els seus efectes depenen de les circumstàncies concomitants particulars tant del remei com de les característiques físiques del malalt, amb la possibilitat que sigui necessari adaptar les quantitats o la manera d'administrar-lo a les diferències geogràfiques $\mathrm{o}$ individuals. De tota manera, fins i tot quan es parteix del testimoni d'un savi, cal comprovar si aquest especifica els particulars. En el cas que ho faci, s'han de respectar; si no els especifica prou, Arnau recomana cautela: convé comparar la complexió de totes dues zones geogràfiques i la complexió del medicament amb altres de similars ja coneguts.

La prevenció que mostra davant l'aplicació d'un remei d'origen no culte fa dubtós que el reconeixement teòric de la possibilitat d'aprendre terapèutiques del poble tingui en Arnau una traducció pràctica. No és estrany, doncs, que en la 

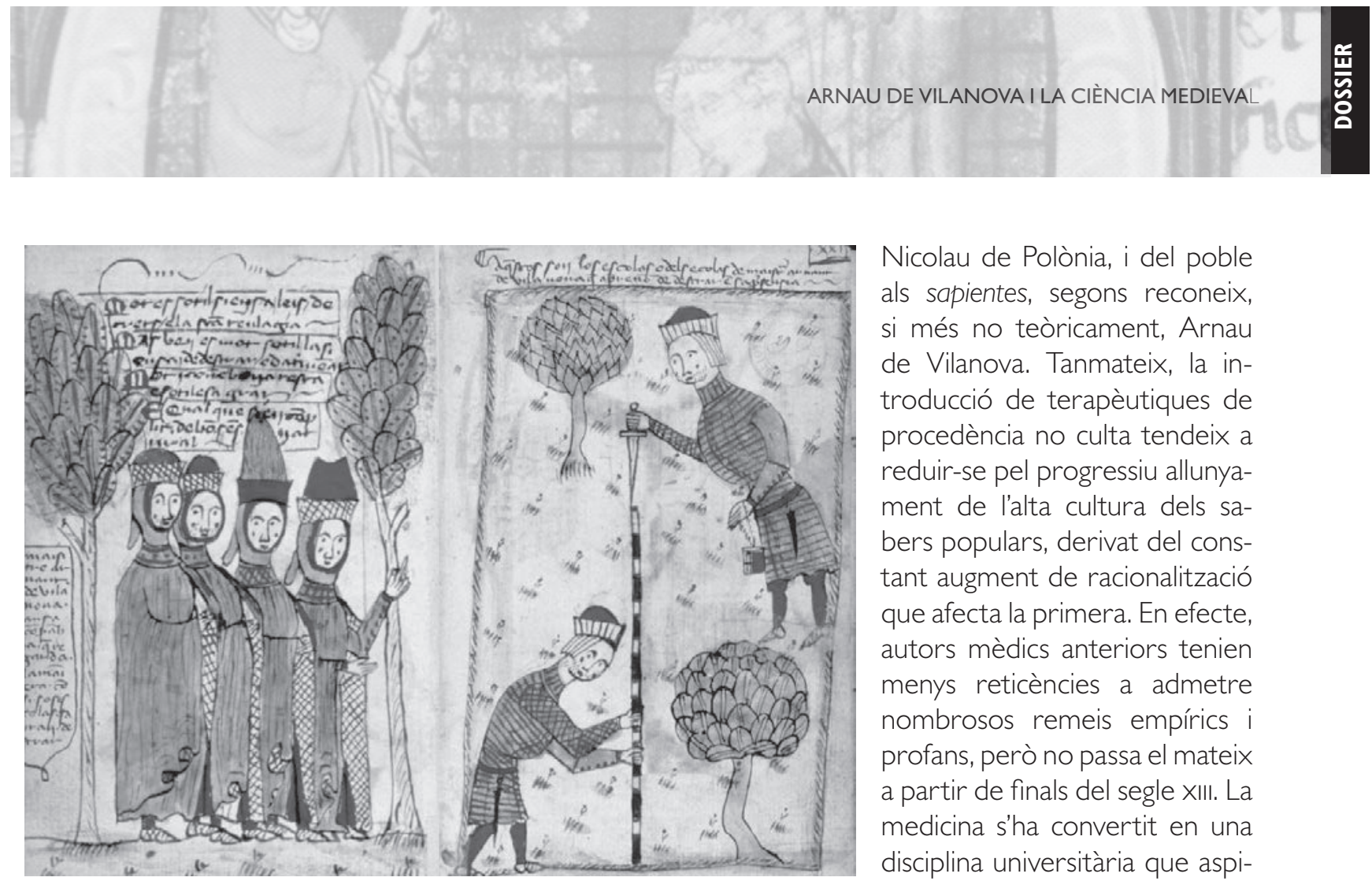

Nicolau de Polònia, i del poble als sapientes, segons reconeix, si més no teòricament, Arnau de Vilanova. Tanmateix, la introducció de terapèutiques de procedència no culta tendeix a reduir-se pel progressiu allunyament de l'alta cultura dels sabers populars, derivat del constant augment de racionalització que afecta la primera. En efecte, autors mèdics anteriors tenien menys reticències a admetre nombrosos remeis empírics i profans, però no passa el mateix a partir de finals del segle XIII. La medicina s'ha convertit en una disciplina universitària que aspira a ser considerada una scientia, Arnau de Vilanova representat al manuscrit Carpentràs, Bibliothèque Inguimbertine, ms. 327 , ff. $28 \mathrm{v}-29 \mathrm{r}$.

basada en la raó i certificada per seva pràctica real, Arnau extregui la informació sobre les propietats ocultes no pas de sanadors sinó d'autoritats mèdiques. La seva actitud és coherent amb les advertències que en el De consideracionibus operis adreça als metges atrets pels remeis dels sanadors empírics (Demaitre, 1988: 131-34) i desmenteix la imatge d'un Arnau favorable a la medicina empírica transmesa per la tradició.

Amb tot, tampoc s'accepten sense cap prevenció aquests remeis quan tenen un origen llibresc. En procedir de l'experiència aliena, Arnau sovint no sembla recomanar-los amb la mateixa seguretat que un medicament de base racional i insinua la dificultat de dominar totes les variants que influeixen en la proprietas. Al cap i a la fi, el recurs a les propietats ocultes, si bé era àmpliament acceptat en el galenisme contemporani, era minoritari en comparació amb les mesures terapèutiques de base complexional, probablement per desconfiança cap a allò que no es podia explicar a partir d'un fonament racional.

En definitiva, les propietats ocultes apareixen com la via de comunicació principal entre l'alta medicina i la medicina no universitària en tots dos sentits, amb la transmissió de l'àmbit universitari a l'extraacadèmic, com hem vist en el cas de obert dels sabers dels illetrats, sovint titllats de supersticiosos.

\section{Recursos astrològics en les obres mèdiques d'Arnau}

La cosmovisió medieval reconeixia en les propietats ocultes un dels vehicles de la influència astral sobre el món terrenal, com acabem de veure, però alhora acceptava que aquest influx també es produïa a través de les complexions i les qualitats dels astres, i per tant d'una manera racionalment constatable. Així doncs, la realitat de l'influx astrològic era generalment acceptada, però no podem perdre de vista que, al mateix temps, el seu abast era sovint discutit, i l'ortodòxia cristiana recelava de la possibilitat d'endevinar les accions que depenien de les decisions humanes, aspecte del qual s'ocupava l'astrologia judiciària. Ara bé, la majoria de les aplicacions de l'astrologia mèdica no solien ser objecte de controvèrsia perquè tenien com a objecte processos fisiològics, no pas actes que depenen del lliure albir. Aquest és justament l'àmbit de la ciència de les estrelles en el qual l'interès d'Arnau està demostrat, tant per la presència d'una sèrie de llibres sobre astronomia 


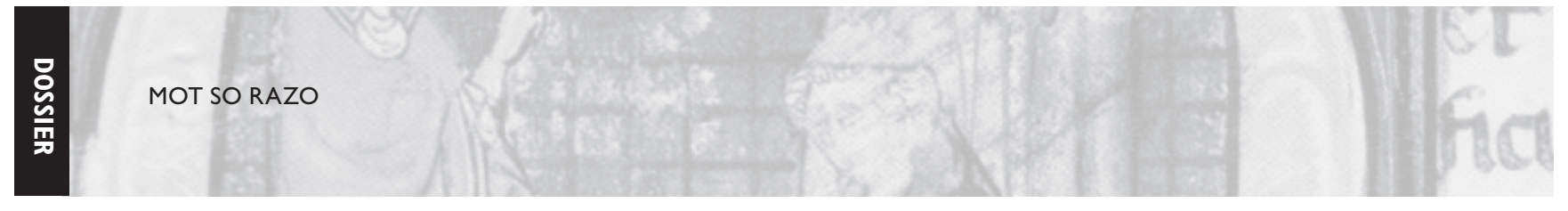

i astrologia a la seva biblioteca com per les de referències disperses al llarg de la seva obra mèdica autèntica (Giralt 2003 i 2006).

En el Speculum medicine (McVaugh, en premsa, cap. 13) Arnau considera l'influx dels cossos celestes com un dels factors externs al cos humà que incideixen en la salut (res non naturales). El classifica entre els factors vinculats a l'aire circumdant (aer), i hi inclou el temps, les variacions estacionals i la influència astrològica. En conseqüència, el metge ha de conèixer-ne els efectes i tenir-los en compte en establir el tractament, sobretot els de les estrelles més influents: el sol i la lluna. De fet, la lluna és l'astre que es té en compte més sovint en l'astrologia mèdica, sobretot a l'hora de decidir el moment més favorable per dur a terme una flebotomia preservativa, és a dir la que no es realitza en una situació d'emergència. Per tant, no resulta sorprenent que la flebotomia o sagnia sigui el procediment mèdic més relacionat amb l'astrologia en els escrits d'Arnau. L'obra que s'estén més sobre aquesta qüestió són les Medicationis parabole, una gran col·lecció d'aforismes, onze dels quals estan dedicats a les condicions astrològiques en relació amb la flebotomia. No es limiten a l'aspecte clínic, sinó que també aborden les causes i els mecanismes de la influència astrològica (Paniagua, Ferre \& Feliu 1990: 59-63).

L'ocasió de veure algunes de les indicacions que donen les Medicationis parabole per a la sagnia aplicades a la pràctica professional d'Arnau la proporciona el Regimen podagre. Es tracta d'un consilium, un breu escrit dirigit a un pacient real que pateix de gota a qui es prescriu un tractament complet. Una de les mesures aconsellades és justament la flebotomia preservativa que, entre altres condicions, s'indica que cal realitzar evitant la lluna en Gèmini. Tal advertència es basa en la melothesia zodiacal, segons la qual el cos humà es divideix en dotze parts, cadascuna sota la influència d'una constel·lació del zodíac, i qualsevol tipus de cirurgia està contraindicada quan la lluna es troba en el signe que domina el membre destinat a ser operat, en aquest cas els braços sota Gèmini (Giralt 2002).

A més de la sagnia, una altra àrea en la qual es van considerar molt sovint les condicions astro- lògiques va ser la recol·lecció de matèria mèdica, no només vegetal, sinó també animal o mineral. Les referències a aquesta pràctica en l'obra d'Arnau són breus i escasses: apareixen només en la Pars operativa i en la primera part, considerada autèntica, de l'Antidotarium (Arnau 1520: f. 127ra i f. 244v). Les propietats particulars, ja siguin nocives o benèfiques, que posseeixen en exclusiva certs individus d'una espècie determinada — vegetal, animal o mineral - es justifiquen per les propietats ocultes de caràcter individual que he esmentat abans.

L'astrologia també té un paper en la prognosi mèdica, especialment en relació amb els dies crítics, en els quals es preveu que es produeixin les crisis periòdiques d'algunes malalties. En el marc d'una exposició més àmplia sobre la prognosi mèdica, l'últim capítol de l'Speculum medicine se centra en els dies crítics (McVaugh, en premsa, cap. 103). Segons Arnau, es deuen en part a l'obra de la natura, en part al moviment de la malaltia. Els principals dies crítics - el quart i setè de cada setmana - són causats per la natura seguint el model del curs de la Lluna. La determinació dels dies crítics, que són els mateixos a tot arreu, es basa en l'experiència dels autors que els transmeten, com Hipòcrates en els Aforismes i Galè en el Passionarius - en realitat aquest últim és una reelaboració a partir de Galè i d'altres autors. Els dies crítics no poden estar fonamentats sobre una base racional millor que en aquests autors i, per tant, prosseguir la recerca més enllà podria traspassar els límits de la medicina i conduir cap a la curiositas, és a dir, la recerca d'un coneixement va i estèril. D'acord amb el seu instrumentalisme mèdic, segons la denominació de McVaugh (2000:139-197). Arnau conclou que al metge li basta conèixer els efectes dels dies crítics i que no tindria sentit investigar-ne les causes.

Totes aquestes aplicacions mèdiques de l'astrologia que tot just hem vist en la medicina arnaldiana — determinació dels dies crítics, l'elecció del moment de la flebotomia i la recollecció de la matèria mèdica - no eren infreqüents en el galenisme baixmedieval. En canvi, resulta força més innovador l'ús de segells astrològiques, una tècnica en la qual Arnau va ser un pioner entre els metges universitaris. 


\section{Pràctica i teoria dels segells astrològics}

El 1301 l'ambaixador Guerau d'Albalat relatava en una carta al rei Jaume II d'Aragó com Arnau de Vilanova havia guarit el papa Bonifaci VIII de mal de pedra (Finke 1902: «Quellen», Xxvi-XXXvii). Tot i que el metge degué proporcionar al papa un tractament complet recollit en un escrit perdut al/ludit per Guerau, aquest només esmenta una de totes les mesures terapèutiques que podem suposar que li va prescriure: un segell d'or gravat quan el Sol era a Leo, que el papa portava en un cinturó. Després d'haver estat tractat per altres metges sense èxit, Bonifaci es va entusiasmar tant amb els eficaços efectes d'aquell segell, al qual atribuïa la seva guarició, que va superar la seva fòbia envers els catalans, causada pel conflicte sicilià, i va exclamar davant Carles d'Anjou que, en la seva experiència, Arnau era l'únic català que feia el bé. Per contra, els cardenals de la cúria es van sorprendre i disgustar tant pel que consideraven un remei poc ortodox com per la recuperació inesperada del papa. De fet, maleïen Arnau perquè tenien coll avall que moriria. És important constatar que el recurs a una imatge astrològica per tractar el papa no va ser un cas aillat en l'activitat professional d'Arnau, com ho demostra l'evidència de set segells de Leo, un de bronze i sis d'or, que van aparèixer entre les seves pertinences a València i a Barcelona després de la seva mort (Chabás 1903). També el seu nebot Joan Blasi, igualment metge, en va posseir (Paul 2012).

Així doncs, el cas d'Arnau és particularment destacat no solament perquè al-ludeix als segells astrològics en els seus escrits mèdics, sinó també perquè hi ha proves documentals que els va emprar en la seva pràctica professional (Weill-Parot 2002: 459-474, Giralt 2006). Els segells astrològics consistien en discos d'or o altres metalls on es gravava la figura del signe zodiacal o la constellació dominant quan eren encunyades. Una de les seves principals finalitats era terapèutica i, en aquest cas, solien basar-se en la melothesia zodiacal. La legitimitat de la seva aplicació, igual que l'ús d'altres tipus d'imatges màgiques, va ser molt controvertida tant en els ambients intellectuals cristians com en els jueus. L'ús de segells astrològics per part d'Arnau aparentment s'ha de relacionar amb la seva connexió indirecta, a través del seu nebot Ermengaut Blasi, germà de
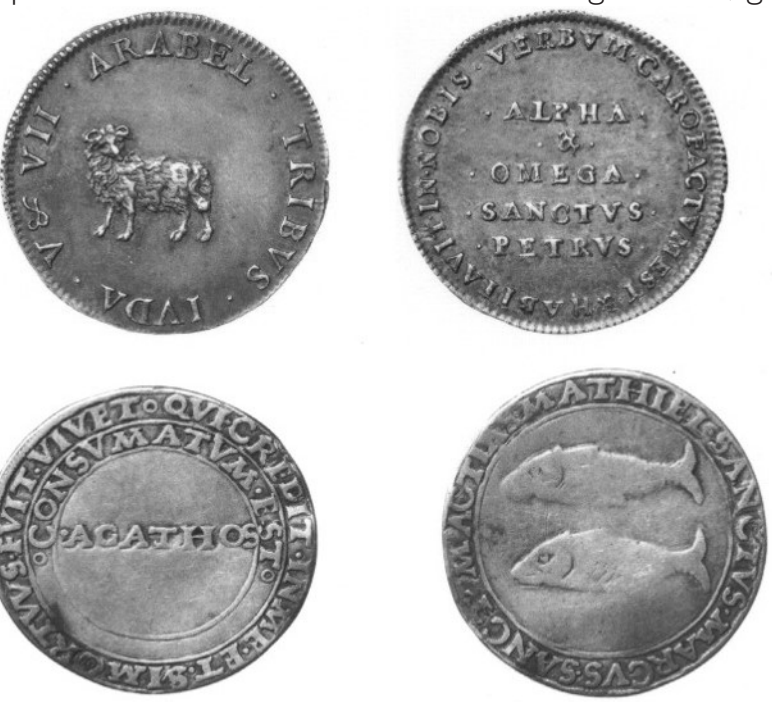

Dues medalles astrològiques (Àries i Pisces), anvers i revers (París, Bibliothèque Nationale de France)

Joan, amb un cercle de traductors i intel-lectuals jueus i cristians a Montpeller.

En l'Speculum medicine (McVaugh, en premsa, cap. 19) i en la Pars operativa (Arnau 1520: f. 127ra), Arnau justifica l'acció del segell de Leo contra el dolor provocat pel mal de pedra a partir de les propietats ocultes imbuïdes en éssers individuals per la posició de les estrelles en el moment de la seva fabricació. Així mateix, hi ha dues altres referències a aquesta mena de segells que no especifiquen sota quin signe han de ser gravats, però mostren la seva possible aplicació contra altres malalties. En la Pars operativa, Arnau inclou els «segells de figures celestes» entre les mesures basades en les propietats ocultes per eliminar les causes de l'alienació mental (Arnau 1520: f. 128va). En segon lloc, els Aphorismi extravagantes recomanen aplicar un segell astrològic indeterminat per tractar la gota (Paniagua \& Gil Sotres 1993: 236). En aquest cas, si tenim en compte la melothesia zodiacal i referències d'altres autors, la imatge ha de ser gravada amb la figura de Pisces, atès que 


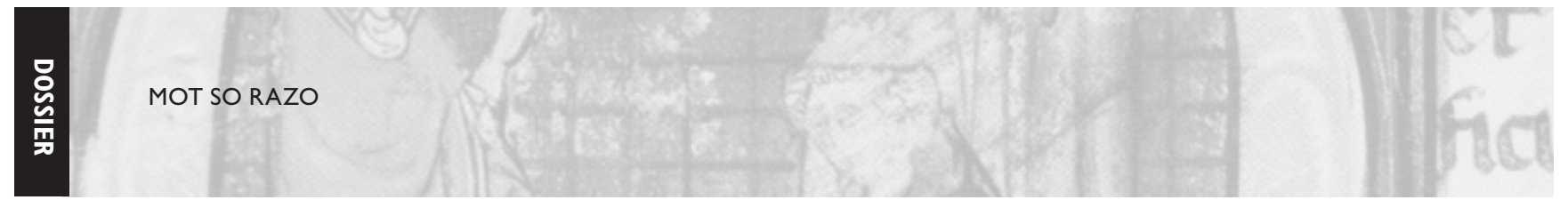

aquest és el signe que domina sobre els peus. Finalment, la part introductòria de l'Antidotarium (Arnau 1520: 244rb) esmenta gemmes imbuïdes de poders per la naturalesa o per l'artesà, que grava imatges corresponents a les constel|lacions, com per exemple una reproducció de Serpentari (Ofiüc) com un antídot contra el verí. Per tant, Arnau podria haver conegut altres segells no basats en els signes del zodíac sinó en altres constel·lacions.

\section{Un temps per a l'astrologia d'Arnau?}

L'astrologia mèdica està, doncs, clarament testimoniada en algunes obres i en la pràctica professional d'Arnau com a complement ocasional i minoritari. Tanmateix, no trobem indicacions astrològiques en molts altres escrits d'Arnau. Aquesta constatació fa pensar si és possible circumscriure l'ús d'Arnau de l'astrologia en un període específic de la seva carrera professional. Un seguit d'indicis suggereixen que se'n va servir només durant l'últim període de la seva vida, des del 1300 fins el 1311, any de la seva mort (Giralt 2006). Ja sabem que va usar el segell de Leo amb el papa Bonifaci el 1301. A més, totes les obres que contenen referències a l'astrologia semblen haver estat escrit en aquest últim període, encara que la majoria són difícils de datar. En realitat, l'única datació precisa és la de les Medicationis parabole, acabades el 1300 d'acord amb el colofó d'alguns manuscrits. Però, de fet, resulta molt indicatiu per establir el límit cronològic per a l'ús d'Arnau de l'astrologia el contrast entre la sèrie d'aforismes sobre la flebotomia pertanyents a les Medicationis parabole i al De consideracionibus operis, atès que aquest darrer, un extens tractat dedicat a la flebotomia escrit un o dos anys abans (Demaitre 1988), no conté cap referència a les condicions astrològiques per a la sagnia. Així mateix, les Medicationis parabole són una referència molt útil per situar altres obres posteriors. L'Speculum medicine (McVaugh, en premsa, cap. 103) les cita com una obra acabada i, per tant, és posterior, probablement finalitzada el 1308. L'Speculum medicine també anuncia la intenció de complementar-les amb altres aforismes sobre les malalties de certs membres específics. Al meu parer, els Aphorismi extravagantes podrien ser part d'aquest projecte inacabat i el Regimen podagre degué ser compost simultàniament a les dues sèries sobre la gota pertanyents a aquesta breu collecció aforística. En conseqüència, totes dues obres podrien haver estat escrites després de l'Speculum o alhora. Finalment, la Pars operativa és una altra obra inacabada datable en els últims anys d'Arnau i, si és autèntica com es creu, la primera part de l'Antidotarium ha estat datada en els primers anys del segle XIV (McVaugh 1995).

Així doncs, és probable que Arnau comencés a emprar l'astrologia al voltant del 1300, quan tenia més o menys seixanta anys d'edat, però era més actiu que mai. Si s'accepta aquesta hipòtesi, la seva introducció a l'astrologia mèdica seria encara més notable i mostraria que va romandre obert a la innovació professional fins al final. Un estímul important per al desenvolupament d'aquesta mena de noves teràpies podria haver estat l'excel.lent acollida que degueren trobar entre els pacients de més alt rang, com el papa Bonifaci.

\section{Les obres astrològiques del corpus arnaldià}

Malgrat que Arnau va justificar alguns remeis astrològics en els seus escrits autèntics, resta oberta la qüestió de si va compondre una obra sencera dedicada a la aplicació mèdica de la ciència de les estrelles. Certament, s'han transmès diversos tractats d'astrologia mèdica sota el nom d'Arnau en manuscrits medievals $i$ en les primeres edicions modernes. Tot i així, ipodem estar segurs de la seva autenticitat quan tants textos de tota mena li van ser apòcrifament atribuiits i la seva fama com astròleg va ser un dels aspectes de la seva llegenda? Sens dubte cal revisar l'autenticitat de cadascun d'aquests tractats.

L'autenticitat del De aqua vite simplici et composita ha suscitat dubtes però encara no ha estat descartada (Calvet 2011: 82-91; Paniagua 1994: 72). És un tractat estructurat majoritàriament d'acord amb la melothesia: s'hi indiquen preparacions alcohòliques destilllades de vi (aqua vite) per a les malalties de cada part del cos quan la lluna surt pel signe del zodíac que la domina. Tanmateix, els deu manuscrits que transmeten aquesta 


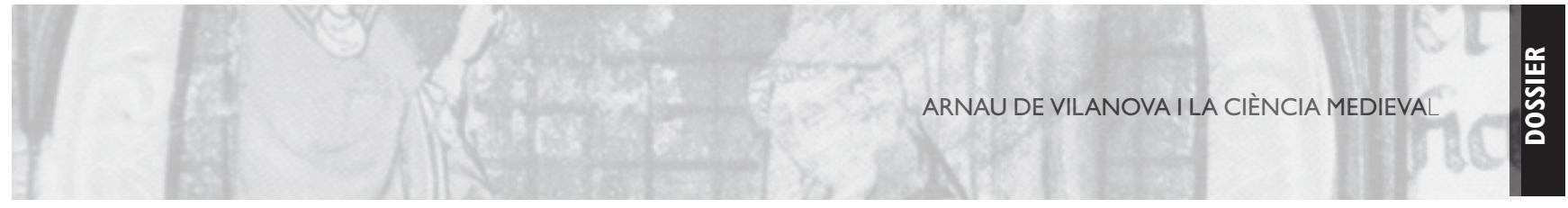

obra, impresa una vegada al voltant de 1477, són tardans, del segle $\mathrm{XV}$, i a parer meu el contingut i l'estil indiquen que és apòcrifa (Giralt, en premsa): se centra en l'aqua vite, que poques vegades s'esmenta en les obres autèntiques d'Arnau i, quan ho és, se l'anomena aqua ardens. El recurs a un remei universal, com aquí l'aqua vite, resulta estrany a la medicina galenista d'Arnau. A més, algunes de les seves principals fonts - Constantí l'Africà, Pere Hispà i Tedorico Borgognoni- mai o gairebé mai són citats per Arnau, molt reticent a esmentar autors llatins medievals. A més, el seu estil no és totalment lliure de la mística pròpia dels textos alquímics, i s'hi empra de tant en tant la segona persona, mentre que Arnau sempre utilitza expressions impersonals en els seus tractats mèdics.

D'altra banda, hi ha una sèrie d'escrits atribuits a Arnau que se centren en les imatges astrològiques. El més conegut és el De sigillis, transmès per vuit manuscrits $i$ imprès en les edicions generals renaixentistes de l'obra arnaldiana. S'hi donen instruccions per fabricar un segell per al tractament de les malalties dels membres que cada signe del zodíac domina segons la melothesia zodiacal: s'hi han de gravar la imatge del signe, lletres hebrees i noms religiosos i oracions. L'han considerat apòcrif Paniagua (1994: 76-77) i Weill-Parot (2002: 477-496; 2004), mentre que l'ha considerat parcialment autèntic Federici-Vescovini (2005), editora del text. La meva opinió és que és fals per dues raons. En primer lloc, la creença de l'autor que els segells d'Àries i Libra poden protegir dels diables contradiu el propòsit de l'epístola d'Arnau contra la nigromància: combatre la creença que un ésser humà és capaç de dominar els dimonis. La mateixa epístola també rebutja la idea que el poder de les estrelles allunya els esperits (Giralt 2005: 219, 226-227). En segon lloc, si bé els segells que hi són descrits tenen bàsicament objectius mèdics, dos d'ells, de nou Àries i Libra, en tenen d'altres: la protecció dels dimonis, dels perills i dels desastres naturals, l'obtenció de guanys materials i psicològics, i l'eliminació dels pecats. Aquests efectes no són compatibles amb l'orientació inequívocament mèdica de l'astrologia d'Arnau i la separació entre religió i ciències profanes que defensa.

A banda del De sigillis, N. Weill-Parot (2002:

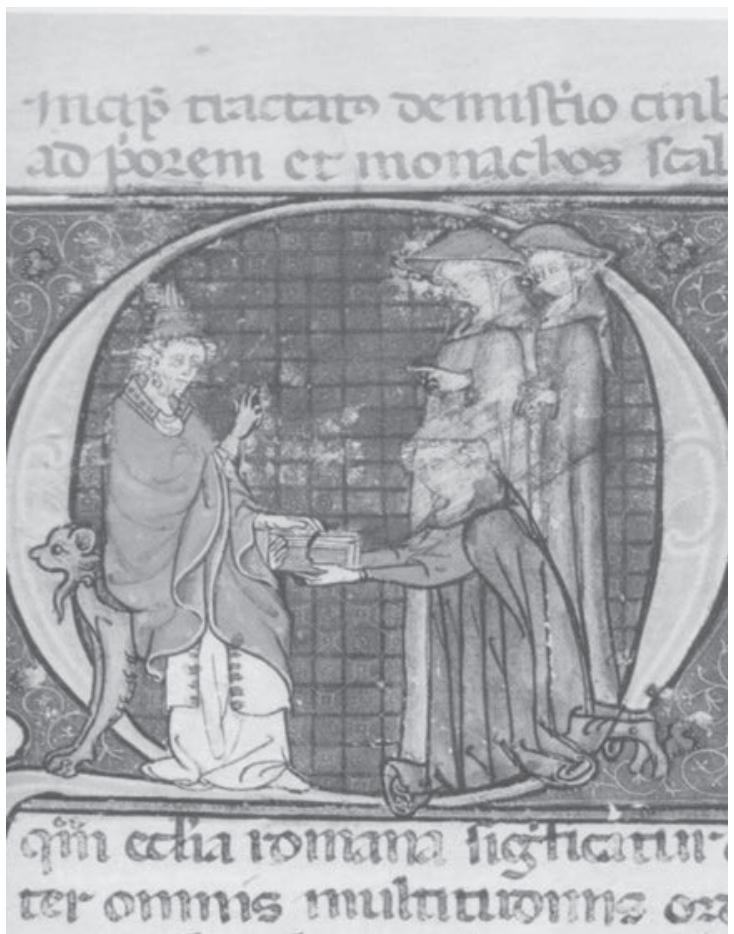

Arnau de Vilanova davant Bonifaci VIII o Climent V (Tractatus de mysterio cymbalorum ecclesie, Roma, Biblioteca Corsiniana, 40. E. 3., f. 1r, detall).

477-496 i 2004) ha cridat l'atenció sobre dos altres escrits sobre imatges astrològiques mèdiques associats amb el nom d'Arnau de diferents maneres, com a autor o reelaborador: el De duodecim imaginibus Hermetis és un breu text amb instruccions per gravar dotze imatges amb les figures dels signes del zodíac amb la finalitat de curar els membres corresponents, mentre que el Sigillum Leonis se centra en el segell de Leo. Altres llibres d'aquest tema vinculats al seu nom van ser el De sigillis duodecim signorum, esmentat en el famós Antipalus maleficiorum per Johannes de Trittenheim (1508) i conservat en un còdex de Gant, el Liber faciendi sigilla i una còpia vaticana del De quindecim stellis, quindecim lapidibus, quindecim herbis et quindecim imaginibus, en la qual es diu que s'hi inclouen algunes addicions realitzades per Arnau (Giralt, en premsa). Al meu parer, la conclusió de N. Weill-Parot sobre aquesta mena d'escrits és correcta: Arnau va adquirir fama com a metge que feia servir segells astrològiques gràcies a les referències que hi va fer dins les seves obres autèntiques i va esdevenir una autoritat en aquest camp. Aquesta és la raó per la qual el seu 


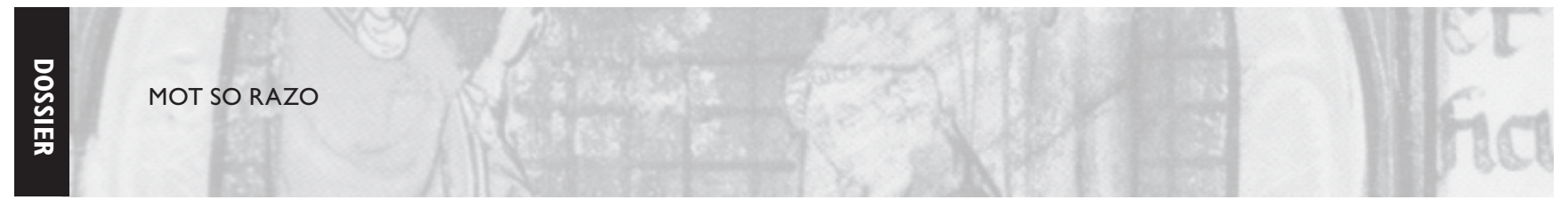

nom va ser emprat com a garantia en textos sobre aquest tema.

De tota manera, la més difosa, amb diferència, de les obres astrològiques atribuïdes a Arnau és una introducció a l'astrologia mèdica titulada Introductorium ad iudicia astrologie quantum pertinet ad medicinam. De fet, és un dels tractats d'astrologia mèdica medievals escrits originalment en llatí que més va circular: se n'han trobat fins a 75 manuscrits llatins, es va traduir dos cops a l'hebreu, al segle XIv, i un a l'alemany, al segle Xvı. Cal advertir, però, que les còpies llatines pertanyen a dues versions del tractat —una, més nombrosa, completa; l'altra només conté la segona part-. i moltes d'elles són anònimes, incompletes o tenen títols diferents (De iudiciis astronomie, De astronomia, Capitula astrologie...), de manera que la identificació d'aquest tractat no sempre resulta fàcil i alguns dels seus exemplars s'ha cregut que corresponien a obres diferents. El seu enorme èxit s'explica perquè presenta els fonaments de l'astrologia per a la seva aplicació mèdica de manera didàctica i orientada a la pràctica. El tractat es divideix en dues parts principals: la primera consisteix en una breu introducció a l'astrologia general en la qual, però, es posa èmfasi en alguns aspectes especialment útils per a la medicina, mentre que la segona part se centra específicament en l'astrologia mèdica. Ha estat considerada una obra possiblement autèntica (Diepgen 1911; Paniagua 1994: 76-77) i recentment s'ha editat a partir d'un sol manuscrit del segle xv (Dell'Anna 1999: II, 133-144).

Tanmateix, l'estudi de la seva tradició textual i del seu contingut indica que no va ser realment obra d'Arnau (Giralt, en premsa): degué circular prèviament de manera anònima, però la creixent difusió del text va requerir un autor famós en l'àmbit de l'astrologia mèdica com Arnau, i així se li va adscriure apòcrifament a fi de donar-li més prestigi. Les dues còpies datades més antigues (1310-1311 i 1318), una d'elles contemporània a Arnau, són anònimes. Només un dels set manuscrits de la primera meitat del segle XIV assenyala que Arnau n'és l'autor, mentre que l'atribució es va fent més freqüent durant la segona part de la centúria i, sobretot, al llarg del segle Xv, quan arriba a la meitat aproximada de les còpies. D'altra banda, també es poden trobar raons en contra de l'autoria d'Arnau en el contingut de l'Introductorium si es compara amb l'aplicació mèdica de l'astrologia documentada en les seves obres autèntiques o en la seva pràctica. Les imatges astrològiques i, en concret, el segell de Leo són el recurs astrològic més testimoniat d'Arnau. Tanmateix, I'Introductorium només hi fa una breu

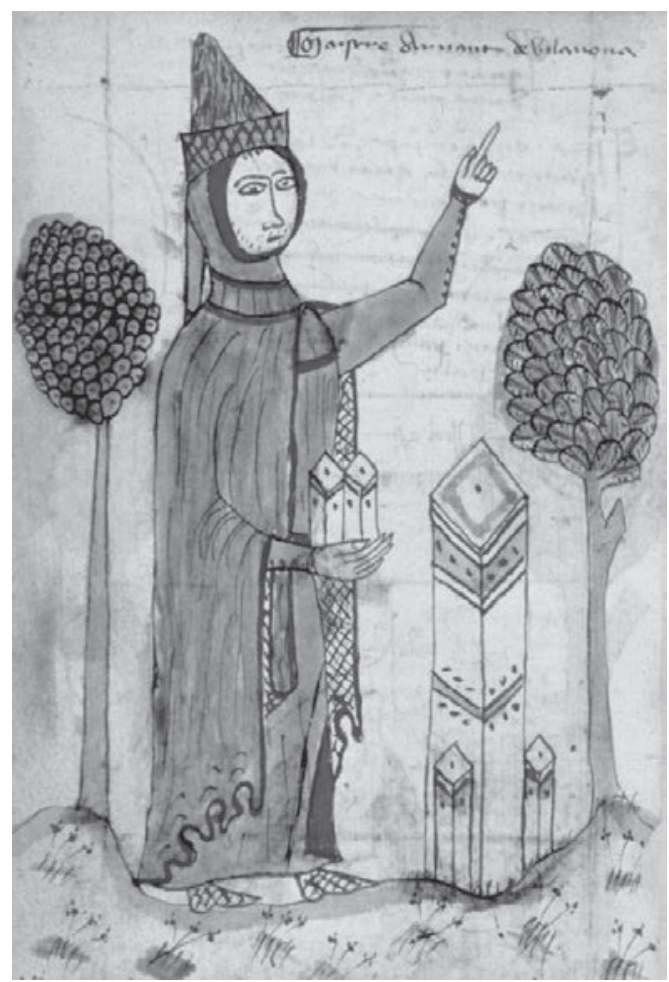

Arnau de Vilanova representat al manuscrit Carpentras, BI, ms. 327 , f. $98 \mathrm{v}$.

referència. A més, l'autoritat en les imatges astrològiques citada per l'Introductorium és Thabit ibn Qurra, mentre que Arnau només cita Hermes. Una altra tècnica en la qual hem vist que Arnau utilitza l'astrologia és la flebotomia, però en l'Introductorium només hi ha una indicació breu específicament relacionada amb aquesta tècnica. En canvi, es dedica més espai a altres procediments evacuatius, com ara laxants i emètics, que no veiem sotmesos a les condicions astrològiques en Arnau. Encara més, l'Introductorium i I'Speculum medicine tenen un enfocament molt diferent en relació amb els dies crítics. Finalment, la presentació de les idees està pobrament organitza- 
da en contrast amb les obres d'Arnau, sobretot en la segona part.

Així doncs, després de comparar el contingut de les obres astrològiques atribuïdes a Arnau amb el dels escrits autèntics i analitzar-ne la tradició textual, la conclusió és que, en realitat, Arnau no va escriure cap tractat que es pugui qualificar d'astrològic. La meva opinió és que la seva dedicació a l'astrologia va ser tardana i més aviat superficial, i no hi va aprofundir prou com per compondre un tractat sobre aquest tema. Com passava sovint, la seva fama - exagerada però no absolutament infundada en el cas de l'astrologia mèdica - va atreure l'atribució de textos que circulaven anònimament per proporcionar-los més credibilitat.

\section{Un metge del seu temps}

Els sabers màgics i astrològics, juntament amb el conjunt de les ciències grecoaràbigues, arriben a la Cristiandat Ilatina a través de les traduccions de l'àrab. Durant el segle XIII i els primers compassos del XIV són sotmesos a un procés de filtració per tal d'integrar les idees i les pràctiques compatibles amb la fe cristiana i rebutjar les que no ho són. En el marc d'aquest procés, en el qual els intellectuals escolàstics debaten quins són els límits entre la màgia natural i la màgia demoníaca o nigromància, s'evidencien diverses sensibilitats a l'hora d'acceptar l'origen natural dels recursos màgics: mentre que alguns autors com Tomàs d'Aquino es mostren més preocupats pel perill d'incórrer en el coneixement illícit (curiositas), que pot provocar la caiguda dels seus practicants en mans dels dimonis, altres com Roger Bacon, Pietro d'Abano o Arnau de Vilanova se senten més atrets per les promeses del nou coneixement transmès per les traduccions. Les dues variants principals que serveixen per diferenciar totes dues actituds són la posició davant el poder de l'ànima i davant el domini tècnic de les propietats ocultes. En efecte, la postura més oberta d'Arnau queda palesa en defensar que les propietats ocultes no tan sols són pròpies de tota una espècie determinada (forma specifica), sinó també de certs individus, creats sota les condicions astrològiques adequades, i això justifica d'una banda el poder extraordinari que té l'ànima de certes persones i, de l'altra, l'aprofitament tècnic de la màgia natural, com veiem en el cas de les imatges astrològiques. En canvi, Tomàs d'Aquino només accepta la forma specifica, de manera que rebutja que les propietats ocultes puguin pertànyer a individus concrets i ser canalitzades per la tècnica. Així, restringeix en gran mesura l'abast de la màgia natural mentre amplia la intervenció dels dimonis (Giralt 2011).

Malgrat que en aquest treball m'he centrat en els aspectes magiconaturals i astrològics de l'obra i de l'activitat professional d'Arnau, no voldria pas haver donat una visió distorsionada de la seva medicina —un risc ben real si pensem en el pes desproporcionat que han adquirit aquests aspectes en el record que la tradició ha guardat d'ell. Ha de quedar clar que les mesures fonamentades en la màgia natural o en l'astrologia són minoritàries dins la medicina d'Arnau i solen ocupar un Iloc secundari. Com és natural, la seva importància varia segons la malaltia a tractar: és més present en la lluita contra el dolor, els verins i els trastorns mentals, potser per la dificultat del seu tractament. D'altra banda, les tècniques sanitàries més subjectes a l'astrologia són la flebotomia, la determinació dels dies crítics i la recol-lecció de matèria mèdica, per bé que la primera de les tres és la que mereix més atenció en l'obra d'Arnau.

Escrits d'orientació pràctica com el Regimen podagre o els Aphorismi extravagantes són els que més útils poden ser per fer-nos una idea de l'espai que ocupaven en la medicina arnaldiana la màgia natural i l'astrologia: en el primer s'observa que algunes de les instruccions donades per a la flebotomia són de caire astrològic; més endavant, en la cura del dolor, després d'haver donat un gran nombre de prescripcions dietètiques i un ampli ventall de fàrmacs, apareix, com un últim recurs complementari dels altres i descrites breument, un seguit d'aplicacions basades en la màgia natural. Entre els darrers dels vint Aphorismi extravagantes en trobem un que, explícitament, aconsella un simple, la berbena, per les propietats ocultes que té, i un altre que recomana un segell astrològic (Paniagua \& Gil Sotres 1993: 236). 
Per tant, cal evitar la temptació de magnificar la importància d'una classe de remeis que actualment ens poden resultar més sorprenents. El fet de donar-los més relleu del que tenien en el conjunt d'una terapèutica va ser sens dubte un dels principals factors que van contribuir a la formació del mite d'Arnau. Cal defugir el risc de perpetuar la imatge d'un Arnau ocultista, potser més atractiva per a alguns que la del rigorós teòric $\mathrm{i}$ professional de la medicina que va ser.

En el sentit oposat, de vegades s'ha suposat que les suspensions, igual que els segells astrològics, eren interpretats per Arnau i pels altres metges que els empraven a la manera del que avui s'entendria com un placebo. Ben al contrari, mestre Arnau justifica sobre la base de les propietats d'origen astral, en el marc de la seva concepció del cosmos, aquest tipus de recursos en obres adreçades a estudiants de medicina $\mathrm{i}$ metges. Per tant, no hi ha dubte que ell creia en les seves virtuts i en els seus efectes. Pensar que Arnau o altres metges medievals consideraven que la màgia natural només aportava un efecte placebo seria caure en l'extrem contrari: minimitzar el recurs a pràctiques màgiques i astrològiques pels prejudicis d'una ortodòxia religiosa o de la mentalitat racionalista del segle XXI. Als segles XIII i XIV la màgia i l'astrologia ocupaven una posició no gens comparable a la que poden tenir en el nostre món, on es troben en una situació marginal en relació amb l'evolució del pensament científic o filosòfic. No es pot negar que en aquell temps moltes de les ments més brillants i obertes s'hi interessaven, de manera semblant a com ho farien en el Renaixement.

Així doncs, esvaït el seu mite, la recerca contemporània ha anat perfilant un Arnau ben ortodox $\mathrm{i}$ integrat en el pensament de la seva època, si més no en el camp de la medicina i la filosofia natural, ja que la seva obra espiritual sí va xocar clarament amb la doctrina oficial. Hi haurà qui encara consideri el seu interès per les arts ocultes un tribut excessiu al seu temps. En canvi, per a d'altres, la nova imatge que es va definint cada vegada amb més claredat resultarà decebedora, descolorida, i s'estimaran més la figura tradicional d'Arnau. En realitat, convertit ja en una de les personalitats més estudiades de les ciències de
l'Edat Mitjana llatina, la seva figura guanya consistència $\mathrm{i}$ alçada intellectual en la mesura que perd pintoresquisme, i es consolida com un dels cims de la medicina medieval. 


\section{Bibliografia citada}

ARnaU de Vilanova, 1520: Opera, Lió: Guillaume Huyon.

AVOMO = Arnaldi de Villanova Opera Medica Omnia.

Batllori, Miquel (ed.), 1947: Obres catalanes. Volum I: Escrits religiosos, pròleg de Joaquim Carreras i Artau, Barcelona: Barcino.

Calvet, Antoine, 2011: Les œuvres alchimiques attribuées à Arnaud de Villeneuve: grand œuvre, médecine et prophétie au Moyen-Âge, París-Milà: S.É.H.A.-Archè.

ChabÁs, Roque, 190z: «Inventario de los libros, ropas y demás efectos de Arnaldo de Villanueva», Revista de Archivos, Bibliotecas y Museos, 9, 11-49.

DelL'AnnA, Giuseppe, 1999: «Dies critici»): la teoria della ciclicità delle patologie nel xıv secolo, Galatina: Congedo.

Demaitre, Luke (ed.), 1988: Arnau de Vilanova, Tractatus de consideracionibus operis medicine sive de flebotomia, intr. Luke Demaitre i Pedro Gil Sotres, Barcelona: Universitat de Barcelona (AVOMO, IV).

Diepgen, Paul, 1911: «Studien zu Arnald von Villanova, IV: Arnalds Stellung zur Magie, Astrologie und Oneiromantie», Archiv für Geschichte der Medizin, 5/1-2, 88-115

EAMON, William \& Gundolf KEIL, 1987: «Plebs amat empirica: Nicholas of Poland and his critique of the mediaeval medical establishment», Sudhoffs Archiv, 71/2, 180-196.

Federici-VescovinI, Graziella, 2005: «l sigilli cosidetti Arnaldiani», Traditio, 6o, 201-242.

FINKE, Heinrich, 1902: Aus den Tagen Bonifaz VIII, Münster Aschendorffsche Buchhandlung.

GIRALT, Sebastià, 2002: «The consilia attributed to Arnau de Vilanova»», Early science and medicine, 7/4 $311-356$.

GIRALT, Sebastià, 2003: «Arnaldus astrologus? La astrología en la medicina de Arnau de Vilanova», Medicina e historia, 2003/2, 1-15.

GIRALT, Sebastià (ed.), 2005: Arnau de Vilanova, Epistola de reprobacione nigromantice ficcionis (AVOMO, VII.1), Barcelona: Universitat de Barcelona-Fundació Noguera.

GIRALT, Sebastià, 2006: «Medicina i astrologia en el corpus arnaldià», Dynamis, 26, 15-38.

GIRALT, Sebastià, 2008: «Proprietas. Las propiedades ocultas según Arnau de Vilanova», Traditio, 63, 327-360.

GIRALT, Sebastià, 2011: «Magia y ciencia en la Baja Edad Media: la construcción de los límites entre la magia natural y la nigromancia (c1230-C1310)», Clío \& Crimen, 8, 15-72.

GIRALT, Sebastià, 2013a: «The Legend of Arnau de Vilanova, from the Middle Ages to the Early Modern Times», Micrologus: Natura, Scienze e Società Medievali, 21, 411-444

GIRALT, Sebastià, 2013b: «Aristoteles imperfectus. Natural Divination, Dream and Prophecy in the Latin Middle Ages (1210-1310)», Die mantischen Künste und die Epistemologie prognostischer Wissenschaften im Mittelalter ed. Alexander Fidora, ColòniaWeimar-Viena: Boehlau, 23-59.

GIRALT, Sebastià, 2017: «The Melancholy of the Necromancer in Arnau de Vilanova's Epistle against Demonic Magic», Demons and IIIness from Antiquity to the Early-Modern Period, ed. Siam Bhayro i Catherine Rider Leiden-Boston: Brill, 271-290.

GIRALT, Sebastià, en premsa: «The Astrological Works Attributed to
Arnau de Vilanova: the Question of their Authenticity»), Geomancy and Other Forms of Divination ed. Alessandro Palazzo, Irene Zavattero, Florència: SISMELEdizioni del Galluzzo.

MARtí, Sadurní, 2009: «Francesc Eiximenis i la màgia», Mot so razo, 8, 54-67.

McVaugh, Michael (ed.), 1975: Arnau de Vilanova, Aphorismi de gradibus, Granada-Barcelona: Universitat de Barcelona (AVOMO, II).

McVaugh, Michael (ed.), 1985: Arnau de Vilanova, Tractatus de amore heroico-Epistola de dosi tyriacalium medicinarum, Barcelona: Universitat de Barcelona (AVOMO, III)

McVaugh, Michael, 1995: «Two texts, one problem: the authorship of the Antidotarium and De venenis attributed to Arnau de Vilanovay, Arxiu de Textos Catalans Antics, 14, 75-94.

McVaugh, Michael (ed.), 2000: Arnau de Vilanova, Tractatus de intentione medicorum, Barcelona: Universitat de Barcelona-Fundació Noguera (AVOMO, V.1)

McVaugh, Michael (ed.), 2014: Arnau de Vilanova, Expositio super aphorismo Hippocratis «In morbis minus» - Repetitio super aphorismo Hippocratis «Vita brevis», introd. Michael R. McVaugh i Fernando Salmón, Barcelona: Universitat de Barcelona-Fundació Noguera (AVOMO, XIV).

McVaugh, Michael (ed.), en premsa: Arnau de Vilanova, Speculum medicine, Barcelona: Universitat de Barcelona-Fundació Noguera (AVOMO, XIII).

Paniagua, Juan Antonio, 1994: Studia arnaldiana: trabajos en torno a la obra médica de Arnau de Vilanova, C. 1240-1311, Barcelona: Fundación Uriach $18 z 8$. 
Paniagua, Juan Antonio, Lola Ferre \& Eduard FeliU (eds.), 1990: Medicationis Parabole - Pirqé Arnau de Vilanova, Barcelona: Universitat de Barcelona - Fundació Noguera (AVOMO, VI.1).

Paniagua, Juan Antonio \& Pedro GIL SOTRES (eds.), 1993: Commentum in quasdam parabolas et alias aphorismorum series: Aphorismi particulares, Aphorismi de memoria, Aphorismi extravagantes, Barcelona: Universitat de Barcelona-Fundació Noguera (AVOMO, VI.2).

PAUL, Pierre, 2012: «Le livre de raison de Jean Blaise, médecin du roi Robert», La France Latine: Revue d'Études d'Oc, n. s., 154, 9-151.

SUDHOFF, Karl, 1916: «Antipocras, Streitschift für mystische Heilkunde in Versen des Magisters Nikolaus von Polen», Archiv für Geschichte der Medizin, 9, 31-52.

Weill-Parot, Nicolas, 2002: Les «images astrologiques» au Moyen Âge et à la Renaissance: spéculations intellectuelles et pratiques magiques (XII-XVe siècle), París: Champion.

Weill-Parot, Nicolas, 2004: «Astrologie, médecine et art talismanique à Montpellier: les sceaux astrologiques pseudoarnaldiens», L'Université de Médecine de Montpellier et son rayonnement (XIII'-XV' siècles), ed. Daniel Le Blévec, Thomas Granier, Turnhout: Brepols, 133-143.
PAUL, Pierre, 2012: «Le livre de raison de Jean Blaise, médecin du roi Robert», La France Latine: Revue d'Études d'Oc, n. s., 154, 9-151.

SUDHOFF, Karl, 1916: «Antipocras, Streitschift für mystische Heilkunde in Versen des Magisters Nikolaus von Polen», Archiv für Geschichte der Medizin, 9, 31-52.
Weill-Parot, Nicolas, 2002: Les «images astrologiques» au Moyen Âge et à la Renaissance: spéculations intellectuelles et pratiques magiques (XII-XVe siècle), París: Champion.

Weill-Parot, Nicolas, 2004: «Astrologie, médecine et art talismanique à Montpellier: les sceaux astrologiques pseudoarnaldiens», L'Université de Médecine de Montpellier et son rayonnement (XIII-XVe siècles), ed. Daniel Le Blévec, Thomas Granier, Turnhout: Brepols, 133-143.

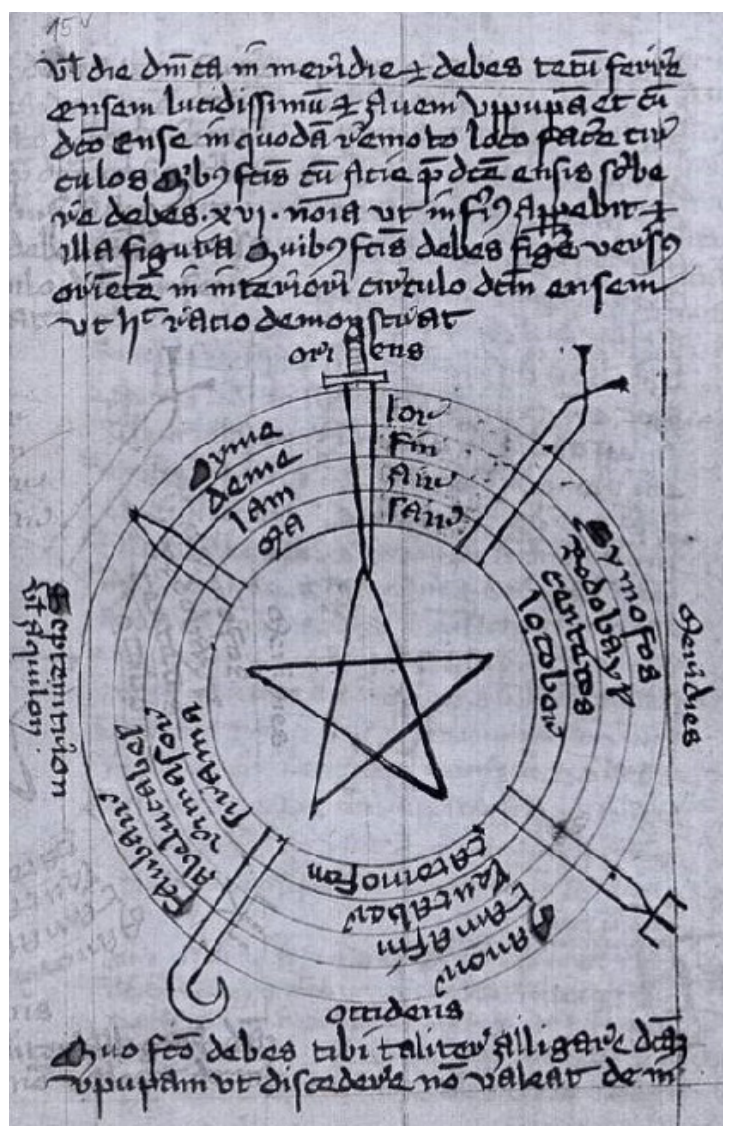

Figura nigromàntica, Munic, BSB, Codex Latinus Monacensis, 849, ff. $3 r-108 v$ 